\title{
Numerical Analysis and Prediction of Coal Mine Methane Drainage Based on Gas-Solid Coupling Model
}

\author{
Mingyun TANG, Pengxian ZHENG, Chunshan ZHENG, Zuxiang HU, Jinhui WANG, Guanglong DAI
}

\begin{abstract}
Methane drainage using boreholes is one of the most effective means of preventing coal mine methane disasters. However, the distributions of stress and permeability around the borehole and the effective influence radius of methane drainage are not clearly known. To solve this problem, a mathematical model of gas-solid coupling of coal rock was first established in this study based on the Kozeny-Carman equation. In this model, the coal rock was considered as a fracture-porosity dual medium. Methane's flow was seepage in the fracture system and diffused in the pore system. Second, the finite volume method was used to discretize the coupling model. The Newton-Raphson iteration and generalized minimal residual algorithm method were used to solve the nonlinear coupling equation after diffusion. Finally, Fortran language was used to simulate the process of methane drainage using a borehole. Results showed that there was respectively stress concentration on the left and right sides of the borehole. This area was associated with the lower permeability in these zones and destroyed the borehole, which is the one of the main reasons for the low efficiency of methane drainage. The relationship between the effective influence radius and the drainage time could be described by a power function. The effective influence radius of the borehole, cumulative methane drainage volume, and residual methane content distribution obtained by simulation were well consistent with the data obtained by the actual measurements, which proves the credibility of the gas-solid coupling and solving methods. This study provides some theoretical reference for methane drainage and the solution of multi-physics field coupling model in coal mines.
\end{abstract}

Keywords: Coal mine methane; Effective influence radius; Finite volume method; Gas-solid coupling; Maximum principal stress; Numerical simulation

\section{INTRODUCTION}

Coal mine methane (CMM) is a clean and highly efficient fuel. However, it can cause serious disasters, which can threaten the safety of mine production [1-5]. Thus, methane control is significant for coal mining. At present, borehole drainage is one of the most effective means of extracting CMM. It cannot only decrease the dangers of coal mining but also obtain clean energy and reduce pollution [6-10]. However, the efficiency of methane drainage is generally low. Some boreholes are destroyed by the stress of surrounding rocks during drilling and methane drainage, leading them to collapse. The flow attenuation of some boreholes is very quick. Some boreholes cannot eliminate methane outburst after methane drainage. All these problems can influence and restrict the safety of mine production.

The permeability of coal seams is one of the most vital parameters that can influence the seepage of gas in the coal rock. It can directly affect the methane drainage efficiency of the borehole. The stress of surrounding rocks in coal seams can change their permeability distribution. At the same time, methane pressure can also affect the effective stress distribution of the coal seam, so the deformation of coal rocks is also influenced. Thus, a coupling interaction exists between the stress of the coal rocks and the seepage of methane $[11,12]$. The permeability of the coal rock is influenced by the stress of the surrounding rock. Thus, the stress distribution of the coal rock around the borehole and the influences of the stress distribution on the permeability need to be investigated.

When multiple boreholes operate simultaneously, the unreasonable distance between the boreholes will cause methane outburst to become incompletely eliminated in the zone of methane drainage by the boreholes, or the flow attenuation becomes very quick, affecting the methane drainage efficiency [13, 14]. The distance between boreholes depends on the effective influence radius of methane drainage by the boreholes. Thus, to improve the methane drainage efficiency using boreholes and provide basis for the reasonable layout of the distance between boreholes, the relationship between the effective influence radius and the drainage time must be studied [15].

\section{STATE OF THE ART}

The permeability of the coal seam is the basis for studying the seepage of gas, which plays an important role in gas migration. Currently, the permeability of the coal seam has been the subject of many relevant researches. By studying the volume strain in stress-strain and permeability of rock samples, $\mathrm{Lu}$ et al. analyzed the influences of factors such as stress and porosity on the permeability of porous rock. Combined with KozenyCarman's model, Lu et al. (2002) presented the characterization relation formula of the permeability of rock in the entire stress-strain process [16]. Li et al. introduced the principle of effective stress in porous media into the seepage of fluid-solid coupling. According to the equilibrium condition, the stress equation was established, and the dynamic models of permeability and porosity were derived according to physical characteristics of the seepage of fluid-solid coupling. On this basis, the mathematical model of the seepage of fluid-solid coupling in the saturated porous media was constructed. Li's (2003) research results provided a theoretical basis for studying the fluid-solid coupling in porous media [17]. Connell et al. established a gas-solid coupling numerical model based on geomechanical assumptions. To investigate the applicability of the model to CMM drainage, the simulator SIMEDII was used to simulate gas migration in a hypothetical coal seam, and the simulator FLAC3D was used to solve the geomechanical response. The simulations showed that the mechanical behavior of the coal seam and the surrounding geology complicate the permeability and gas migration of coal. The assumption of constant vertical stress leads to the significant difference between the permeability estimated by Shi-Durucan and the actual 
permeability, especially at early times during production. Connell et al. (2009) analyzed the distribution of vertical normal stress and shear stress around the borehole but not the distribution of the maximum principal stress around the borehole and its effect on permeability [18]. Lin et al. considered the effect of gas adsorption expansion in the gas-solid coupling model. They found that the permeability of coal seams increases gradually with increasing drainage time, which is divided into three sections according to the increase rate. The increase of permeability was sharp in 0-30 days, gradual in 30-220 days, and stable after 200 days. The relationship between the permeability of coal seams and the volume adsorption constant was negative linear, and that between the permeability of coal seams and the pressure adsorption constant was negative exponential [19]. Wei et al. established a gas-solid coupling model based on fractureporosity dual medium. The classical Kozeny-Carman equation was used to solve the permeability of coal seam. The mass exchange between the fracture and pore system of the coal seam was taken into consideration. The threedimensional simulation and analysis of the methane drainage in the borehole were carried out by using the multi-physics coupling software COMSOL. The results showed that the fluid-solid coupling model, in which the fracture-porosity dual medium was considered, was more consistent with the actual situation than a single-seepage field model. However, Wei et al. (2016) did not analyze the stress field and permeability distribution around the borehole [20]. Liu et al. improved the traditional fluidsolid coupling model. The deformation of coal body, diffusion of gas in the matrix, and gas seepage in the fracture system were considered in the coal rock permeability model, and the gas pressure in the coal was divided into matrix pressure and fracture pressure. Compared with the traditional fluid-solid coupling model, more factors were considered in this model. Liu's (2017) model required more known parameter values such as fracture pressure and pore pressure, which are difficult because of the complexity of coal seam geological conditions. Therefore, verifying the correctness of the model is relatively difficult [21]. Zhang et al. regarded coal seam as a combination of fracture and matrix systems. The mass exchange between the matrix and the fracture is considered. Different gas pressures exist in the matrix and the fracture [22]. Zhang's (2018) model is more comprehensive in considering the seepage of gas in coal seam, but it ignores the diffusion effect of gas in matrix systems. In addition, determining the initial permeability of fracture and matrix by experiments in coal seams is difficult.

The above studies mainly solved the gas-solid coupling model using commercial software such as FLAC3D and COMSOL to analyze the law of gas migration in borehole drainage and the evolution of coal seam permeability. However, few studies investigated the maximum principal stress and permeability distribution around the borehole under the stress of the roof. In addition, few comparisons were made with the actual test data of methane drainage in coal mines from many aspects.

The effective influence radius is an important basic parameter for borehole design and has been studied by many scholars. Wu et al. established a single gas seepage model, but the effects of gas adsorption, gas desorption, and coal deformation on gas extraction were ignored. FLAC3D was used to determine the extraction radius. Wu's (2012) model assumes that the coal seam has an infinite thickness such that the influence of the coal seam roof and floor boundary on the gas extraction radius is ignored. However, it has a great impact on gas extraction radius when a coal seam is thin [23]. Li et al. established a gas-solid coupling model and found that the effective influence radius gradually increases, but the growth rate is reduced gradually by the multi-physics coupling software. Li's (2014) study provided the permeability change curve of extraction under different times, but the function between the effective influence radius and drainage time was not obtained [24]. Li et al. established a mathematical relation among methane drainage radius, coal parameters, and drainage time according to the mass conservation law and Darcy's law. The model assumes that the extraction quantity of borehole and drainage time have a simple exponential relationship. The effective influence radius was $2.70-3.72 \mathrm{~m}$ with the drainage of 60 days by calculation. Li's (2014) model is too simple because only the seepage of methane is considered [25]. Lu et al. obtained the methane drainage radius of borehole by numerical simulations based on gas-solid coupling mathematical model and determined the relation between the borehole distance and methane drainage radius of single borehole. However, only the gas pressure was compared with the actual gas pressure. The methane content and methane drainage quantity of the borehole were not compared with the field experimental result [26]. Kong et al. used the response surface method and COMSOL to simulate and analyze the effect of initial gas pressure, permeability of coal seam, and borehole radius on effective influence radius of methane drainage. They found that the effective influence radius increased with increasing borehole radius and initial permeability, and the polynomial equation of effective influence radius and these factors was obtained by fitting [27]. Yue et al. established a gas-solid coupling anisotropic seepage model based on the gas permeability test results of anisotropic coal seam and simulation of the variation law of effective influence radius with different borehole orientations. They found that the permeability at the directions of face cleat and butt cleat was larger than that at the vertical direction of cleat, and the relationship of effective drainage radius and drainage time can be expressed by power exponent. However, they did not analyze the influence of roof stress of coal seam on permeability [28]. Chen et al. established a gas-solidliquid coupling model based on an experiment and optimized the spacing and layout of boreholes by COMSOL. They found that the boreholes arranged in rhomboidal form were more beneficial to eliminating gas outburst than those arranged in rectangle form. In this model, the wet strain of coal seam must be considered, but some parameters, such as gas and water relative permeability in coal seam, are difficult to obtain [29].

The above studies obtained the relation between effective influence radius and drainage time based on certain assumptions. Although the method was simple, the factors of gas migration were not comprehensive enough. Some researchers studied the effective influence radius mainly through commercial software FLA3D or COMSOL, 
but their results were too simple compared with the results of field tests.

In the present study, a gas-solid coupling model of coal and gas was established. The permeability was solved using the classical Kozeny-Carman model. The finite volume method (FVM) was used to discretize the coupling model. The Newton-Raphson iterative method developed using Fortran language was used to solve the coupling model. The distribution of maximum principal stress and the permeability around the borehole, which were obtained by simulations, were analyzed in depth. In addition, the cumulative methane drainage volume, residual methane content distribution, and effective influence radius were compared by simulating with the data obtained by the actual measurements in the selected coal mine to verify the reliability of the model. On this basis, the effect of drainage time on the effective influence radius was studied. Our study provides an important theoretical basis for the design of methane drainage and the solution of the multi-physics coupling model.

\section{METHODOLOGY}

\subsection{Mathematical Model of Gas-Solid Coupling in Coal}

Coal consists of coal matrix and fracture [30-31]. The methane in the coal matrix and the fracture is adsorbent and free, respectively, as shown in Fig. 1. In other words, the coal seam is regarded as a fractured-porous dual media. Therefore, a dual-porosity single-permeability model was used. The free methane flowed through the fracture system, whereas the adsorbed methane diffused throughout the pore system. The mass exchange consisted of the transfer between positive and negative mass sources in the two systems.

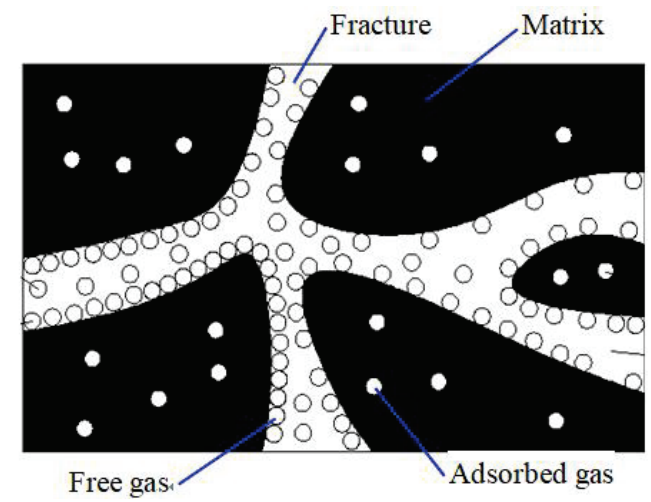

Figure 1 Illustration of coal, which is typically a dual-porosity system

\subsubsection{Basic Hypotheses}

1) The methane in the coal seam is considered as an ideal gas, and its flow in the fracture follows Darcy's seepage law. The migration in the matrix satisfies Fick's laws of diffusion.

2) The deformation of the coal seam obeys the generalized Hooke's law.

3) The coal seam is a homogeneous, isotropic, and fractured-porous dual medium.

\subsubsection{Methane Seepage Equation in the Fracture System}

A micro unit was selected for the computational section of coal. According to the conservation of mass of the free methane in the fracture, the methane mass that flows into the micro unit in all directions minus the methane mass that flows out of the micro unit in all directions plus the methane mass desorbed from the pore system in the micro unit is the methane mass change in the micro unit. For the convenience of computation, the profile of methane drainage from the coal seam borehole was simplified to a two-dimensional physical model. The methane seepage equation can be expressed as follows:

$\frac{\partial(\rho n)}{\partial t}+\nabla \cdot(\rho \bar{V})=q$

where $\rho$ is the free methane density $\left(\mathrm{kg} / \mathrm{m}^{3}\right) ; n$ is the porosity of the micro unit, which is variable and can be obtained by combining the methane pressure field with the coal deformation equation field; $\vec{V}$ is the velocity vector of the methane seepage $(\mathrm{m} / \mathrm{s}) ; q$ is the positive methane mass source desorbed from the micro unit $\left(\mathrm{kg} /\left(\mathrm{m}^{3} \cdot \mathrm{s}\right)\right)$.

\subsubsection{Methane Diffusion Equations in the Pore System}

The pore system and the fracture system exist in the same micro unit. The mass exchange between the borehole and the coal seam only considers the seepage. According to the conservation of mass of the adsorbed methane in the micro unit, the following expression can be obtained:

$\frac{\partial C}{\partial t}+\nabla \cdot m=-q$

where $C$ is the mass of adsorptive methane per unit volume of coal seam $\left(\mathrm{kg} / \mathrm{m}^{3}\right)$ and $m$ is the velocity vector of methane diffusion $\left(\mathrm{kg} /\left(\mathrm{m}^{2} \cdot \mathrm{s}\right)\right)$.

\subsubsection{Control Equations for the Coal Rock Deformation}

For the same micro unit mentioned above, the equilibrium condition of the forces in the $x$ and $y$ directions can be expressed as follows:

$\frac{\partial \sigma_{x}}{\partial x}+\frac{\partial \tau_{y x}}{\partial y}+f_{x}=0$
$\frac{\partial \sigma_{y}}{\partial y}+\frac{\partial \tau_{x y}}{\partial x}+f_{y}=0$

where $f_{x}, f_{y}$ are the body forces in the $x$ and $y$ directions, respectively $(\mathrm{Pa} / \mathrm{m}) ; \sigma_{x}, \sigma_{y}$ are the normal stresses in the $x$ and $y$ directions, respectively $(\mathrm{Pa})$; and $\tau_{y x}, \tau_{x y}$ are the shear stresses on the micro unit $(\mathrm{Pa})$, where $\tau_{y x}=\tau_{x y}$ according to symmetry.

The $y$ direction is regarded as the vertical direction. By incorporating Hooke's law, the geometric equation for coal rock deformation, and the correctional effective stress equation into the above equations, the differential 
equations for the deformation field in which displacement is variable can be obtained as follows [21, 32]:

$E_{S} \frac{\partial^{2} u}{\partial x^{2}}+G \frac{\partial^{2} u}{\partial y^{2}}+(G+\lambda) \cdot \frac{\partial^{2} v}{\partial x \cdot \partial y}-\frac{\partial(\alpha p)}{\partial x}=0$

$E_{s} \frac{\partial^{2} v}{\partial y^{2}}+G \frac{\partial^{2} v}{\partial x^{2}}+(G+\lambda) \cdot \frac{\partial^{2} u}{\partial y \cdot \partial x}-\frac{\partial(\alpha p)}{\partial y}+\rho_{\mathrm{s}} g=0$

where $G=\frac{E}{2 \cdot\left(1+\mu^{\prime}\right)}$ is the shear modulus $(\mathrm{Pa})$ $E_{s}=\frac{E}{1-\mu^{\prime 2}}$ is the compression modulus of the lateral confinement $(\mathrm{Pa}) ; \lambda=\frac{E \cdot \mu^{\prime}}{1-\mu^{\prime 2}}$ is the Lamé constant $(\mathrm{Pa})$; $\alpha$ is the Biot number; $\mu^{\prime}$ is Poisson's ratio; $E$ is the elastic modulus $(\mathrm{Pa}) ; u, v$ are the displacement components in the $x$ and $y$ directions, respectively $(\mathrm{m})$; and $\rho_{\mathrm{s}}$ is the density of the coal in the micro unit $\left(\mathrm{kg} / \mathrm{m}^{3}\right) ; g$ is the gravitational acceleration, equal to $9.81 \mathrm{~m} / \mathrm{s}^{2} ; p$ is the methane pressure $(\mathrm{Pa})$.

\subsubsection{Computation of Coupling Parameters}

With the Langmuir equation, the adsorptive methane concentration can be calculated as follows:

$C=\frac{a b c p p_{n}}{(1+b p) R T}$

where $a$ is the limiting adsorption amount per unit mass that is combustible at the referenced pressure $\left(\mathrm{m}^{3} / \mathrm{kg}\right) ; b$ is the adsorption equilibrium constant $\left(\mathrm{Pa}^{-1}\right)$; $c=\rho_{\mathrm{s}} \cdot \frac{100.0}{100.0+0.31 M} \cdot \frac{100.0-A-M}{100.0}$ is the combustible mass per unit volume $\left(\mathrm{kg} / \mathrm{m}^{3}\right) ; A$ is the ash content of coal $(\%) ; M$ is the moisture content of coal $(\%) ; p_{n}$ is the reference pressure, equal to $101,325 \mathrm{~Pa} ; p_{1}$ is the adsorptive equilibrium pressure of the pore system; $R$ is the methane constant $(\mathrm{J} /(\mathrm{kg} \cdot \mathrm{K}))$; and $T$ is the temperature of the coal seam $(\mathrm{K})$.

The seepage velocity of the free methane, $\vec{V}$, and the diffusion velocity of the adsorptive gas, $m$, are calculated using Darcy's seepage law and Fick's laws of diffusion as follows:

$$
\begin{aligned}
\vec{V} & =-\frac{k}{\mu} \nabla p \\
m & =-D \nabla C
\end{aligned}
$$

where $k$ is the permeability of the fracture system $\left(\mathrm{m}^{2}\right) ; k$ is variable and is a function of the porosity, $n ; \mu$ is the viscosity of the methane $(\mathrm{Pa} \cdot \mathrm{s}) ; D$ is the diffusion coefficient of the methane in the pore system $\left(\mathrm{m}^{2} / \mathrm{s}\right)$; and $p$ is the methane pressure $(\mathrm{Pa})$.

The effects of temperature and methane adsorption and desorption on the porosity of the coal rock are ignored. However, the effect of the pore pressure on the solid skeleton is considered. According to the definition of porosity, the following expression can be obtained [17]:

$$
n=1-\frac{\left(1-n_{0}\right)}{1+\varepsilon_{v}}\left(1-\frac{p-p_{0}}{k_{s}}\right)
$$

where $\varepsilon_{v}$ is the body strain, $k_{s}$ is the solid skeleton modulus of the coal rock $(\mathrm{Pa}), n_{0}$ is the initial porosity, and $p_{0}$ is the initial methane pressure $(\mathrm{Pa})$.

Permeability is a function of the porosity, which can be described by the Carman-Kozeny equation as follows $[16,33]$ :

$$
k=\frac{k_{0}}{1+\varepsilon_{v}}\left[1+\frac{\varepsilon_{v}}{n_{0}}+\frac{\left(p-p_{0}\right) \cdot\left(1-n_{0}\right)}{k_{s} \cdot n_{0}}\right]^{3}
$$

where $k_{0}$ is the initial methane permeability $\left(\mathrm{m}^{2}\right)$.

\subsection{Solution of Gas-Solid Coupling Model}

Eqs. (8) and (9) are substituted into Eq. (1) and Eq. (2), respectively. Then, Eq. (1) is added to Eq. (2). The simplified model can be expressed as follows:

$$
\frac{\partial(\rho n)}{\partial t}+\frac{\partial C}{\partial t}-\nabla \cdot\left(\rho \cdot \frac{k}{\mu} \nabla p\right)=\nabla \cdot(D \nabla C)
$$

Eqs. (5), (6), and (12) describe the dual-porosity singlepermeability gas-solid coupling model of the coal seam. These three equations have three unknown variables $u, v$, $p$; thus, the equations are closed. These equations are nonlinear, and therefore, the numerical solution is necessary.

FVM is the most widely used numerical discretization method in computational fluid dynamics and computational heat transfer [34-37]. It is simpler than finite element method (FEM) in mesh generation. The basic idea of FVM is easy to understand, and its physical explanation can be obtained directly. The advantage of FEM is that it can use irregular meshes to calculate and process complex geometric models. The physical model established in this study is regular, so FVM can meet the calculation requirements. In addition, the gas-solid coupling model established in this study involves gas and stress fields. It will provide great convenience for the design and the implementation of programs if the two fields are discretized and solved by FVM. Therefore, FVM was used to discretize the gas-solid coupling equations in this study. The linear equations of the large and sparse matrix could be obtained through the Newton-Raphson iteration. Finally, generalized minimal residual algorithm method was used to solve linear equations [38].

In this study, the deformation field and the methane field were solved. The deformation field was solved primarily. The two displacement variables obtained were substituted into the coupling models of the permeability and the porosity such that the permeability, $\mathrm{k}$, and porosity, n, were obtained. Then, the methane field was solved. Finally, the methane pressure obtained was substituted into the equations of the deformation field again. When the 
deformation field and methane field were all convergent, the iteration solution of this time step was over. The process for solving the coupling equations is shown in Fig. 2.

Based on the above theoretical study, the Fortran language was used to develop the numerical simulation system of the methane drainage by the boreholes in the coal seam.
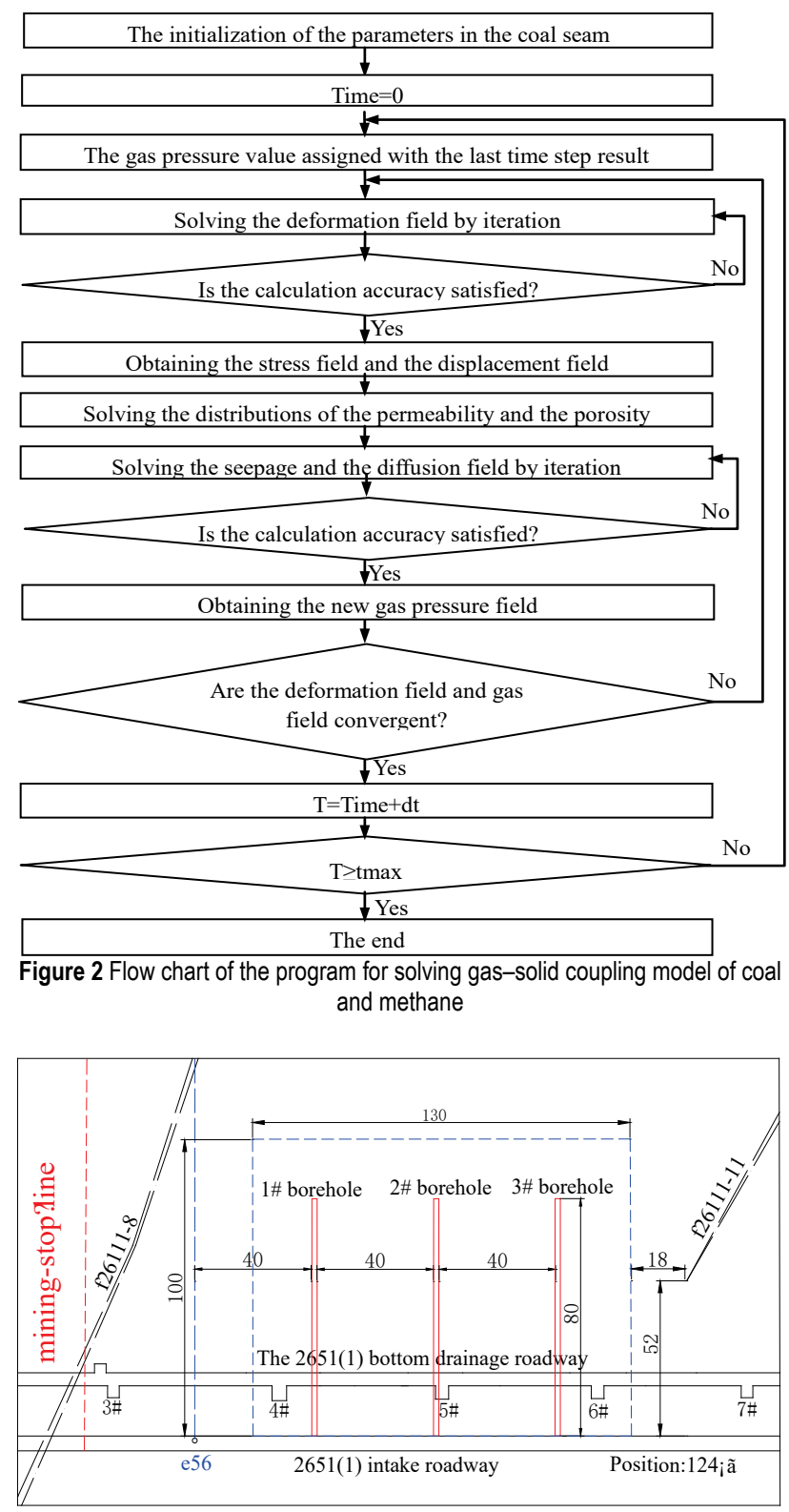

Figure 3 Plan layout of drilling gas extraction test site

\subsection{Numerical Simulation of Borehole Methane Drainage 3.3.1 Research Site Overview}

Coal seam 11-2 in the Panyi Coal Mine in China was selected as the simulated object. The elevation of the ground is $16.0-20.3 \mathrm{~m}$. The elevation of the working face is -600.6 to $-642.0 \mathrm{~m}$. The strike length and the tendency length of the working face are 815.8 and $226.5 \mathrm{~m}$, respectively. The thickness of the coal seam is $0.8-2 \mathrm{~m}$, with an average of $1.7 \mathrm{~m}$. The bulk density is $1470 \mathrm{~kg} / \mathrm{m}^{3}$. The methane pressure is $9.0 \times 10^{5} \mathrm{~Pa}$, and the methane content in the coal seam is $4.11 \mathrm{~m}^{3} / \mathrm{t}$. The effective influence radius of the boreholes at this roadway was investigated. Three boreholes were present, and the study area is shown in Fig. 3. The diameter of the boreholes is $113 \mathrm{~mm}$, and the total length of the boreholes is $80 \mathrm{~m}$. The sealed borehole length is $20 \mathrm{~m}$.

\subsubsection{Gas-Solid Coupling Physical Model}

Working Face 2651(1) has not been mined, and thus the roadway studied was minimally affected by mining activity. The stress distribution of the coal seam roof was homogeneous. The elevation of the study location is -601 $\mathrm{m}$, and the average bulk density of the rock is $2,400 \mathrm{~kg} / \mathrm{m}^{3}$. The stress of the surrounding rock roof was calculated to be $1.415 \times 10^{7} \mathrm{~Pa}$. The two-dimensional physical model is shown in Fig. 4. The physical property parameters of coal seam 11-2 are summarized in Tab. 1.

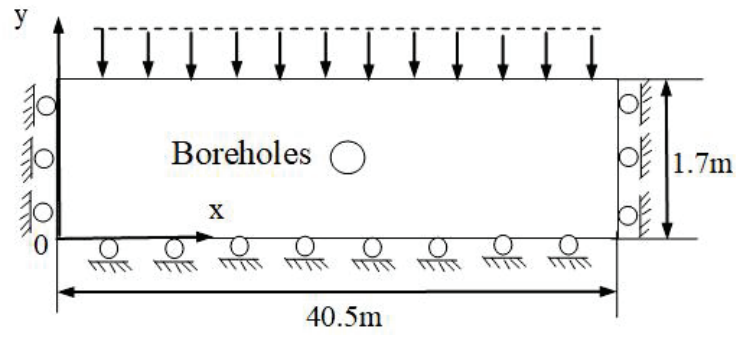

Figure 4 Drilling gas extraction geometry model

Table 1 Physical properties of coal

\begin{tabular}{|l|c|}
\hline \multicolumn{1}{|c|}{ Parameter } & Value \\
\hline Coal seam initial methane pressure $(\mathrm{Pa})$ & $9.0 \times 10^{5}$ \\
\hline Elastic Modulus, $E(\mathrm{~Pa})$ & $3 \times 10^{9}$ \\
\hline Poisson's ratio, $\mu^{\prime}$ & 0.4 \\
\hline Coal density, $\rho_{v}\left(\mathrm{~kg} / \mathrm{m}^{3}\right)$ & 1470 \\
\hline Initial porosity, no $(\%)$ & 3.92 \\
\hline Initial permeability, $k_{0}\left(\mathrm{~m}^{2}\right)$ & $2.5 \times 10^{-17}$ \\
\hline limit adsorption gas volume, $a\left(\mathrm{~m}^{3} / \mathrm{kg}\right)$ & $17.71 \times 10^{-3}$ \\
\hline Adsorption constant, $b\left(\mathrm{~Pa}^{-1}\right)$ & $9.96 \times 10^{-7}$ \\
\hline Diffusion coefficient, $D\left(\mathrm{~m}^{2} / \mathrm{s}\right)$ & $6.0 \times 10^{-12}$ \\
\hline Coal moisture, $M(\%)$ & 1.73 \\
\hline Coal ash, $A(\%)$ & 27.18 \\
\hline
\end{tabular}

\subsubsection{Simulated Boundary and Initial Conditions}

The breathability of the rock in the roof and floor of the coal seam was smaller than that of the coal seam itself. Therefore, the top and bottom boundaries were assumed to be closed. In addition, the size of the borehole was much smaller than the strike length, and thus the boundary in the strike direction (the $x$ direction) was also assumed to be closed. Therefore, the following can be obtained:

$$
\left\{\begin{array}{l}
\left.\frac{\partial p(i, j)}{\partial n}\right|_{\Gamma_{\mathrm{s}}}=0 \\
\left.p(i, j)\right|_{\Gamma_{\mathrm{r}}}=P_{\mathrm{out}}
\end{array}\right.
$$

where $\Gamma_{\mathrm{s}}$ is the computing area boundaries of coal seam, $\Gamma_{\mathrm{r}}$ $\mathrm{s}$ the borehole boundaries, and $P_{\text {out }}$ is the negative pressure of the methane drainage of the borehole $(\mathrm{kPa})$ and has a value of $-1.3 \times 10^{4} \mathrm{~Pa}$.

The stress or displacement of the boundary should be given when solving the deformation field. According to 
Fig. 4, the boundary of deformation field can be obtained as follows:

$$
\left\{\begin{array}{l}
\left.u(i, j)\right|_{\Gamma_{x}}=0 \\
\left.v(i, j)\right|_{\Gamma_{y 1}}=0 \\
\left.\sigma_{y}(i, j)\right|_{\Gamma_{y 2}}=1.415 \times 10^{7} \mathrm{~Pa} \\
\left.\sigma_{\mathrm{n}}(i, j)\right|_{\Gamma_{\mathrm{r}}}=0
\end{array}\right.
$$

where $\Gamma_{x}$ is the boundary in the $x$ direction, $\Gamma_{y 1}$ is the bottom boundary in the $y$ direction, and $\Gamma_{y 2}$ is the top boundary in the $y$ direction.

\section{RESULT ANALYSIS AND DISCUSSION \\ 4.1 Maximum Principal Stress and Permeability Distribution around the Borehole}

The unsteady numerical simulation of methane drainage through a borehole in the coal seam was solved. According to the simulation results of drainage for 30 days, the distribution of the maximum principal stress and the permeability of the coal around the borehole were obtained, as shown in Figs. 5 and 6.

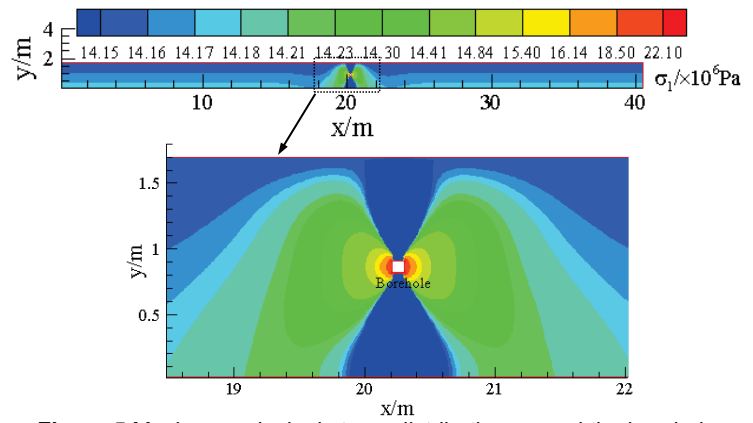

Figure 5 Maximum principal stress distribution around the borehole

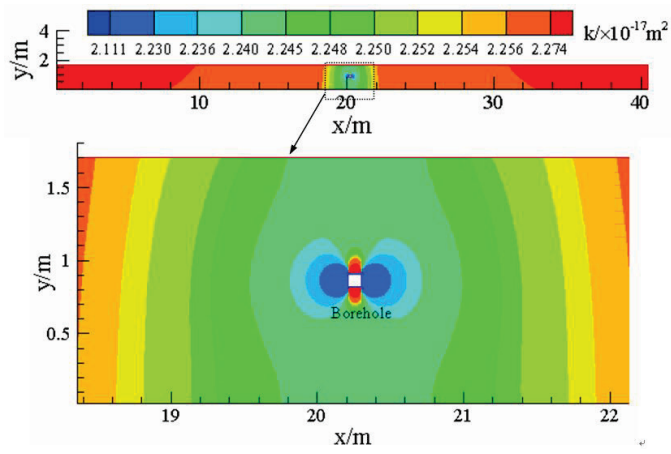

Figure 6 Permeability distribution cloud map around the borehole

Fig. 5 shows that the maximum principal stress distribution around the borehole is varied. The maximum principal stress distributions at the top and bottom of the borehole were approximately triangular. The isoline of the maximum principal stresses in the area away from the borehole showed a stratified depth-dependent distribution because of gravity's influence on the coal seam. An area of stress concentration existed on the left and right sides of the borehole. The maximum principal stress was $2.21 \times 10^{7}$ $\mathrm{Pa}$, but the common principal stress of the coal rock was $1.415 \times 10^{7} \mathrm{~Pa}$ before the borehole was constructed. The maximum principal stress in the stress concentration zone was increased by $56.1 \%$. Fig. 6 clearly shows that the effect of the principal stress of the surrounding rock of the roof causes a decrease in porosity, which results in a decrease in the permeability from $2.5 \times 10^{-17} \mathrm{~m}^{2}$ to $2.27 \times 10^{-17} \mathrm{~m}^{2}$. After the borehole was constructed, the permeability further decreased to $2.11 \times 10^{-17} \mathrm{~m}^{2}$ because of the stress concentration area around the borehole. Compared with the initial permeability, this is a decrease in permeability by $15.6 \%$.

As seen from the bedding borehole arrangement of the coal seam, the left and right sides of the boreholes are the main seepage channels for the methane drainage in the bedding borehole. The stress concentration on the left and right sides of the boreholes not only reduces the permeability but also causes borehole collapse, thus blocking the seepage channels in the borehole chamber. These are the main reasons for the low efficiency of methane drainage in boreholes. Therefore, in addition to hydraulic fracturing, sand injection, and hydraulic cutting to improve the permeability of coal seam on the left and right sides of the boreholes, a pipe with many small holes must be set up in the borehole to construct a gas flow passage. The pipe with many small holes will protect the borehole from damage because it is equivalent to a solid skeleton in coal seam. Fig. 7 shows a diagram of pipes with many small holes after actual compression and destruction in boreholes. As seen in the figure, the pipes with many small holes were deformed due to the surrounding rock stress, but some gaps remained, which created a migration path for gas flow. This migration path could make the methane drainage more durable and effective after setting a pipe with many small holes in the bedding borehole.

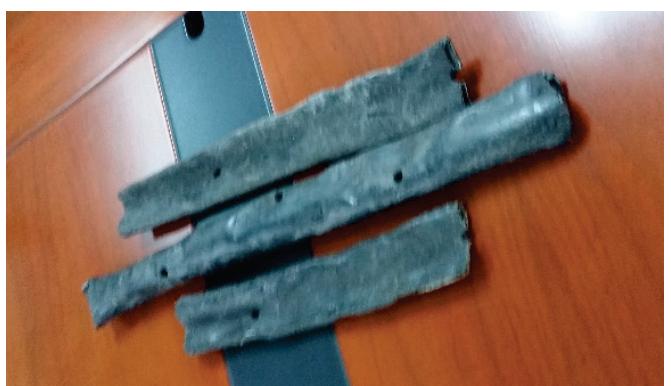

Figure 7 Diagram of pipes with many small holes after actual compression and destruction in boreholes

\subsection{Cumulative Methane Drainage Volume per Day}

We calculated the cumulative methane drainage volume per day in the first month (30 days) according to the volume flow, methane concentration, and drainage time of the three boreholes at the study site. The distribution curves of the actual drainage are shown in Fig. 8. Moreover, we also calculated the cumulative methane drainage volume per day in the first month (30 days) according to the simulation results and the gas chamber length in borehole. The distribution curves of the simulation results are shown in Fig. 8.

Fig. 8 shows that the simulation results are consistent with the results of the actual methane drainage. With the increase of drainage time, the cumulative methane drainage volume per day decreased rapidly, but the decline speed gradually slowed down. Owing to the influence of negative 
pressure during methane drainage, the curves of $1 \#, 2 \#$, and $3 \#$ borehole fluctuated from top to bottom. The cumulative methane drainage volume of the test in the first day was less than that of the simulation result due to the influence of the borehole sealing time.

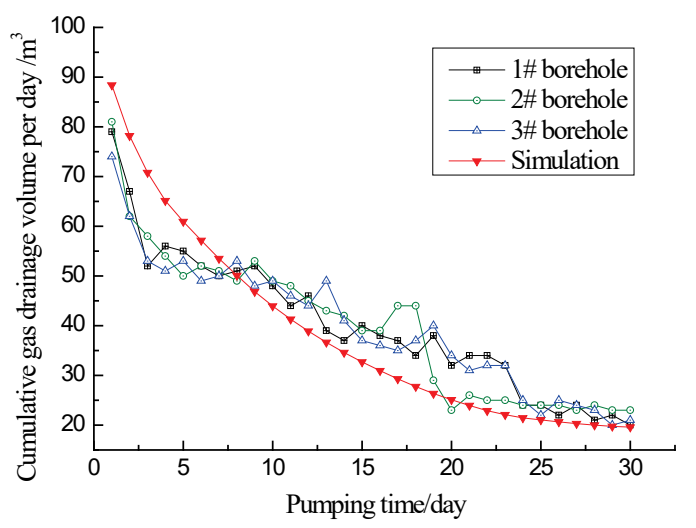

Figure 8 Relationship between the cumulative extraction amount and the extraction time

\subsection{Distribution of Residual Methane Content around the Borehole}

According to the simulation results, the residual methane contents around the borehole after drainage for 30 days were obtained. The methane contents at different distances from boreholes in the direction of $X$ axis are shown in Fig. 9. Moreover, the methane contents at different distances from three boreholes were tested after drainage for 30 days. The test results are also shown in Fig. 9.

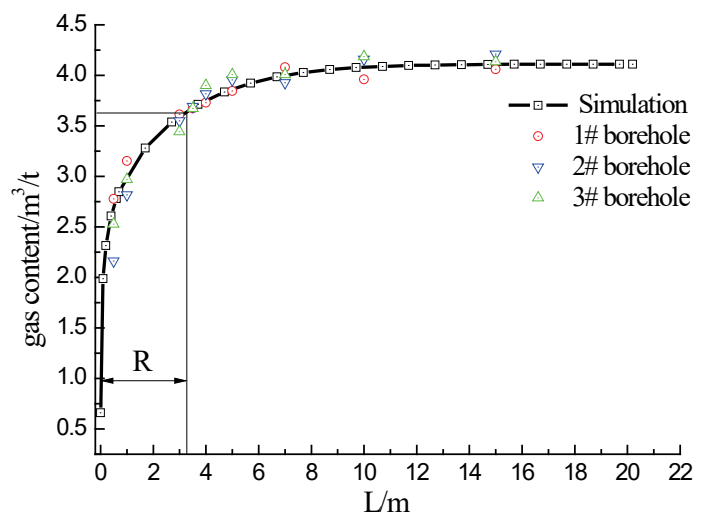

Figure 9 Residual methane content distribution in the direction of $X$ axis

Fig. 9 shows that the residual methane content distribution obtained by simulation coincides with the test results of the three boreholes. The relationship between the methane content and distance from the borehole was exponential. The residual methane content was the lowest at the borehole boundary and increased with increasing distance from the borehole until it approached the initial methane content of $4.111 \mathrm{~m}^{3} / \mathrm{t}$.

According to the relevant regulations [39], if the residual methane pressure is less than $7.4 \times 10^{5} \mathrm{~Pa}$ and the residual methane content is less than $8 \mathrm{~m}^{3} / \mathrm{t}$, the area is not considered to be a methane outburst danger. Therefore, the effective influence radius was defined as the region starting from the wall of the borehole to the region where the pressure did not exceed $7.4 \times 10^{5} \mathrm{~Pa}$. The effective influence radius of bedding drilling was tested using the methane content method. This method was used to test the distribution of methane content around the borehole. The residual methane content around the borehole after methane drainage was tested first, and then the gas pressure distribution around the borehole was calculated according to the Langmuir equation. Finally, if the methane content and methane pressure obtained by the test met the requirements, the area would be considered an effective influence radius range in the experimental site. According to the Langmuir equation, when the residual methane pressure of the experimental site was $7.4 \times 10^{5} \mathrm{~Pa}$, the calculated residual methane content was $3.67 \mathrm{~m}^{3} / \mathrm{t}$. Therefore, when the measured residual methane content was less than $3.67 \mathrm{~m}^{3} / \mathrm{t}$, it was considered to be in an effective influence radius range in the experimental site. The effective influence radius of $1 \#, 2 \#$, and $3 \#$ borehole after drainage for 30 days was $3.0-3.5 \mathrm{~m}$ according to the test results, and the effective influence radius of simulation was $3.15 \mathrm{~m}$ as shown in Fig. 6. Therefore, the simulation results are consistent with the effective influence radius of the actual methane drainage.

\subsection{Prediction of Effective Influence Radius under Different Drainage Times}

Owing to mining on the working face, the actual drainage times of boreholes varied. The drainage time can be approximately 15 days, but it may reach 90 days or more. Therefore, the relationship between the effective influence radius and the drainage time must be simulated and analyzed. The layout of the boreholes should be optimized based on the actual drainage time. Six simulation planes were made to simulate, analyze, and compare the results. The drainage times were 15, 30, 45, 60,75 , and 90 days. The residual methane pressure distributions obtained from the simulations with varying drainage times are shown in Fig. 10. According to the judgment standard for the effective influence radius, the relationship between the effective influence radius and the drainage time is shown in Fig. 11.

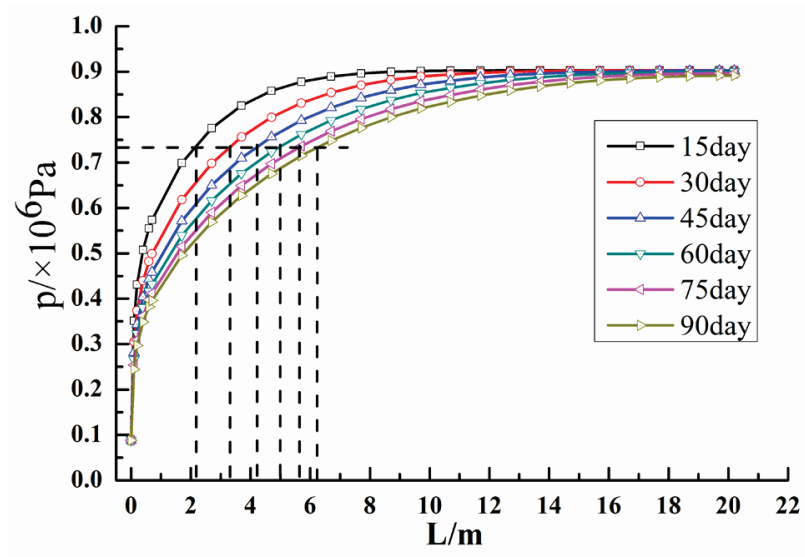

Figure 10 Residual methane pressure distributions along the $X$ axis at varying drainage times

Fig. 10 shows that the residual methane pressure distributions for the different drainage times clearly differed. Owing to the methane drainage, the residual methane pressure around the borehole decreased with 
increasing drainage time. However, the amplitude of the residual methane pressure decrease was reduced gradually at the same location. In addition, the farther away from the borehole, the smaller the effect of drainage time on the residual methane pressure. Fig. 11 shows that as the methane drainage time increased, the effective influence radius also increased, but the increment decreased gradually. The function describing this relationship is given in Eq. (16):

$R=0.43887 \cdot t^{0.59524}$

where $R$ is the radius of the drainage $(\mathrm{m})$ and $t$ is the drainage time (day).

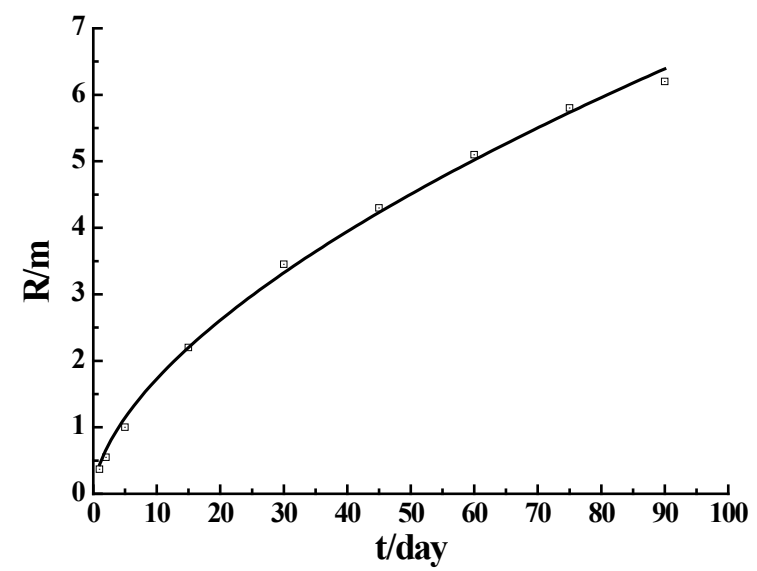

Figure 11 Relationship between effective influence radius and drainage time

\section{CONCLUSIONS}

To obtain the distribution laws of the stress and the permeability of the coal seam around the borehole and the relationship between the effective influence radius and the drainage time, the gas-solid coupling numerical model was established in this study, and the method of solving this numerical model was given. This numerical model was used to simulate the methane drainage by borehole in the coal seam of the experimental coal mine, and the simulation results were analyzed. The following conclusions were obtained:

(1) Stress concentration exists respectively on the left and right sides of the borehole, which leads to lower permeability in this zone and borehole collapse.

(2) The effective influence radius after drainage for 30 days, cumulative methane drainage volume per day, and residual methane content distribution, which were obtained by the simulation, are approximately consistent with the data obtained by the actual measurements in the coal mine.

(3) The greater the drainage time, the larger the effective influence radius. However, the increment decreases gradually. The relationship between the effective influence radius of methane drainage by borehole and the drainage time is a power function.

The FVM and Newton-Raphson iteration were used to solve the gas-solid coupling model established in this study, which was completed by Fortran language. The gassolid coupling model and its solution method could provide researchers who devote themselves to solving the coupling model of multi-physics field with some theoretical basis.
Based on analyses, the distribution laws of the maximum principal stress and the permeability around borehole were obtained, which can play a guiding role in the methane drainage by borehole. Comparison of the simulation result with the data obtained by actual measurements increased the applicability of this study. However, in this study, the deformation equation of the solid was assumed to be elastic deformation, and the plastic deformation caused by the stress of the coal rock was ignored. Thus, the deformation field of the solid obtained by simulation was slightly different from the actual deformation of the coal rock. In future research, the real plastic deformation should be considered to increase the integrality of the model, which will help researchers determine the gas-solid coupling interaction between coal rock and gas.

\section{Acknowledgements}

This work was supported by the National Natural Science Foundation of China (NO. 51774014, 51574009), China Postdoctoral Science Foundation funded project (NO. 2016M592034), Anhui Provincial Natural Science Foundation (1808085ME160).

\section{REFERENCES}

[1] Ziarani, A. S., Aguilera, R., \& Clarkson, C. R. (2011). Investigating the effect of sorption time on coalbed methane recovery through numerical simulation. Fuel, 90(7), 24282444. https://doi.org/10.1016/j.fuel.2011.03.018

[2] Keim, S. A., Luxbacher, K. D., \& Karmis, M. (2011). A numerical study on optimization of multilateral horizontal wellbore patterns for coalbed methane production in Southern Shanxi Province, China. International Journal of Coal Geology, 86(4), 306-317. https://doi.org/10.1016/j.coal.2011.03.004

[3] Tang, M. Y., Jiang, B. Y., Zhang, R. Q., Yin, Z. Q., \& Dai, G. L. (2016). Numerical analysis on the influence of gas extraction on air leakage in the gob. Journal of Natural Gas Science and Engineering, 33, 278-286. https://doi.org/10.1016/j.jngse.2016.05.006

[4] Gan, T., Balmain, B., \& Sigbatullin, A. (2016). Formation evaluation logoff results comparing new generation miningstyle logging tools to conventional oil and gas logging tools for application in Coalbed Methane (CBM) field development. Journal of Natural Gas Science and Engineering, 34, 1237-1250. https://doi.org/10.1016/j.jngse.2016.07.070

[5] Xia, T. Q., Zhou, F. B.; Wang, X. X., Kang, J. H., \& Pan, Z. J. (2017). Safety evaluation of combustion-prone longwall mining gobs induced by gas extraction: A simulation study. Process Safety and Environmental Protection, 109, 677-687. https://doi.org/10.1016/j.psep.2017.04.008

[6] Karacan, C. Ö., Diamond, W. P., \& Schatzel, S. J. (2007). Numerical analysis of the influence of in-seam horizontal methane drainage boreholes on longwall face emission rates. International Journal of Coal Geology, 72(1), 15-32. https://doi.org/10.1016/j.coal.2006.12.007

[7] Packham R., Cinar Y., \& Moreby R. (2012). Simulation of an enhanced gas recovery field trial for coal mine gas management. International Journal of Coal Geology, 85(34), 247-256. https://doi.org/10.1016/j.coal.2010.11.013

[8] Danesh, N. N., Chen, Z. W., Aminossadati, S. M., Kizil, M. S., Pan, Z. J., \& Connell, L. D. (2016). Impact of creep on the evolution of coal permeability and gas drainage performance. Journal Natural Gas Science and Engineering, $33,469-482$. 
https://doi.org/10.1016/j.jngse.2016.05.033

[9] Zhang, H. R., Pera, L. S., Zhao, Y. J., \& Sanchez, C. V. (2015). Researches and Applications on Geostatistical Simulation and Laboratory Modeling of Mine Ventilation Network and Gas Drainage Zone. Process Safety and Environmental Protection, 94, 55-64. https://doi.org/10.1016/j.psep.2014.10.003

[10] Hummel, J. A., Ruiz, F. A., \& Kelafant, J. R. (2018). Quantifying the benefits of coal mine methane recovery and use projects: Case study on the application of in-mine horizontal pre-drainage boreholes at gassy coal mines in India and the optimization of drainage system design using reservoir simulation. Environmental Technology \& Innovation, 10, 223-234. https://doi.org/10.1016/i.eti.2018.03.003

[11] Hu, Z. X., Sun, J., \& Tang, M. Y. (2018). An Experimental Study on the Interaction Law of the Pore Gas Pressure and Stress in Gassy Coals. Tehnički vjesnik-Technical Gazette, 25(4), 1154-1161. https://doi.org/10.17559/TV-20180805103717

[12] Zou, Q. L. \& Lin, B. Q. (2018). Fluid-Solid Coupling Characteristics of Gas-Bearing Coal Subjected to Hydraulic Slotting: An Experimental Investigation. Energy \& Fuels, 32(2), 1047-1060. https://doi.org/10.1021/acs.energyfuels.7b02358

[13] Zhou, F. B., Wang, X. X., \& Liu, Y. K. (2014). Gas drainage efficiency: an input-output model for evaluating gas drainage projects. Natural Hazards, 74(2), 989-1005. https://doi.org/10.1007/s11069-014-1224-2

[14] Liu, Z. D., Cheng, Y. P., Jiang, J. Y., Li, W., \& Jin, K. (2017). Interactions between coal seam gas drainage boreholes and the impact of such on borehole patterns. Journal of Natural Gas Science and Engineering, 38, 597607. https://doi.org/10.1016/j.jngse.2017.01.015

[15] Yu, T., Lu, P., Sun, J. H., \& Deng, Z. (2012). Measurement of Effective Drainage Radius Based on Gas Flow and Pressure of Boreholes. Journal of Mining \& Safety Engineering, 29(4), 596-600.

[16] Lu, P., Shen, Z. W., Zhu, G. W., \& Fang, E. C. (2002). Characterization of and Experimental Study on the Permeability of Rock-samples During Complete Stressstrain Course. Journal of University of Science and Technology of China, 32(6), 678-684.

[17] Li, P. C., Kong, X. Y., \& Lu, D. T. (2003). Mathematical modeling of flow in saturated porous media on account of fluid-structure coupling effect. Journal of Hydrodynamics, 18(4), 419-426.

[18] Connell, L. D. (2009). Coupled flow and geomechanical processes during gas production from coal seams. International Journal of Coal Geology, 79(1-2), 18-28. https://doi.org/10.1016/j.coal.2009.03.008

[19] Lin, H. F., Huang, M., Li, S. G., Zhang, C., \& Cheng, L. H. (2016). Numerical simulation of influence of Langmuir adsorption constant on gas drainage radius of drilling in coal seam. International Journal of Mining Science and Technology, 26(3), 377-382. https://doi.org/10.1016/j.ijmst.2016.02.002

[20] Wei, J. P., Li, B., Wang, K., \& Sun, D. H. (2016). 3D numerical simulation of boreholes for gas drainage based on the pore-fracture dual media. International Journal of Mining Science and Technology, 26(4), 739-744. https://doi.org/10.1016/j.jmst.2016.05.028

[21] Liu, T., Lin, B. Q., Yang, W., Liu, T., Kong, J., Huang, Z. B., Wang, R., \& Yang, Z. (2017). Dynamic diffusion-based multifield coupling model for gas drainage. Journal of Natural Gas Science and Engineering, 44, 233-249. https://doi.org/10.1016/j.jngse.2017.04.026

[22] Zhang, S. W., Liu. J. S., Wei, M. Y., \& Elsworth, D. (2018). Coal permeability maps under the influence of multiple coupled processes. International Journal of Coal Geology, 187, 71-82. https://doi.org/10.1016/j.coal.2018.01.005

[23] Wu, B., Hua, M. G., Feng, X. Y., \& Guo, S. G. (2012). Study on Methods of Determining Gas Extraction Radius with Numerical Simulation. Procedia Engineering, 45, 345-351. https://doi.org/10.1016/j.proeng.2012.08.169

[24] Li, B., Wei, J. P., \& Li, P. (2014). Numerical Simulation on Gas Drainage of Boreholes in Coal Seam Based on GasSolid Coupling Model. Computer Modelling \& New Technologies, 18(12A), 418-424.

[25] Li, Z. W., Lin, B. Q., Guo, M. G., \& Gao, Y. B. (2014). Determination on Effective Influence Radius of Gas Drainage Through Borehole Based on One-dimensional Radial Flow. Coal Science and Technology, 42(12), 62-64.

[26] Lu, Y., Shen H. M., Qin, B. T., Zhang L. L, Ma, H. F., \& Mao, T. L. (2015). Gas drainage radius and borehole distance along seam. Journal of Mining \& Safety Engineering, 32(1), 156-162.

[27] Kong, X. G., Wang, E. Y., Liu, X. F., Li, N., Chen, L., Feng, J. J., Kong, B., Li, D. X., \& Liu, Q. L. (2016). Coupled analysis about multi-factors to the effective influence radius of hydraulic flushing: Application of response surface methodology. Journal of Natural Gas Science and Engineering, 32, 538-548. https://doi.org/10.1016/j.jngse.2016.04.043

[28] Yue, G. W., Wang, B. B., Cao, H. S, Zhao, Y., \& Liang W. M. (2017). Influence of effective drainage radius by borehole orientation along seam with anisotropic permeability. Journal of China Coal Society, 42(S1), 138-147.

[29] Chen, Y. X., Xu, J., Peng, S. J., Yan, F. Z., \& Fan, C. J. (2018). A Gas-Solid-Liquid Coupling Model of Coal Seams and the Optimization of Gas Drainage Boreholes. Energies, 11(3), 1-21. https://doi.org/10.3390/en11030560

[30] Lu, M., Connell, L. D., \& Pan, Z. J. (2008). A model for the flow of gas mixtures in adsorption dominated dual-porosity reservoirs incorporating multi-component matrix diffusion-Part II numerical algorithm and application examples. Journal of Petroleum Science and Engineering, 62(3-4), 93-101. https://doi.org/10.1016/j.petrol.2008.06.002

[31] Kumar, H., Mishra, M. K., \& Mishra, S. (2018). Effect of Permeability and Geomechanical Properties on Coal Matrix During CBM Production - An Overview. Journal of Engineering Science and Technology Review, 11(2), 160173.

[32] Zhu, W. C., Wei, C. H., Li, S., Wei, J., \& Zhang, M. S. (2013). Numerical modeling on destress blasting in coal seam for enhancing gas drainage. International Journal of Rock Mechanics and Mining Sciences, 59, 179-190. https://doi.org/10.1016/j.jijmms.2012.11.004

[33] Si, H., Guo, T., \& Li, X. H. (2011). Analysis and numerical simulation of fluid-structure coupling of gas drainage from boreholes. Journal of Chongqing University, 34(11), 105110.

[34] Tang, M. Y., Shi, A. F., \& Wang, X. H. (2013). Adaptive Mesh Refinement Method for Thermal Recovery of Heavy Oil with Light Component using Steam Injection. Chinese Quarterly of Mechanics, 34(1), 25-31.

[35] Rakibuzzaman, M., Kim, K., Kim, H. H., \& Suh, S. H. (2017). Energy saving rates for a multistage centrifugal pump with variable speed drive. Journal of Power Technologies, 97(2), 163-168.

[36] Rakibuzzaman, M., Kim, K., Kim, H. H., \& Suh, S. H. (2017). Three-dimensional CFD Study of Free-Surface Flow in a Sharply Curved $30^{\circ}$ Open-Channel Bend. Journal of Engineering Science and Technology Review, 10(3), 85-89. https://doi.org/10.25103/jestr.103.12

[37] Laguna, A. A., Ozak, N., Lani, A., Deconinck, H., \& Poedts, S. (2018). Fully-implicit finite volume method for the ideal two-fluid plasma model. Computer Physics Communications, 231, 31-44. 
https://doi.org/10.1016/j.cpc.2018.05.006

[38] Saad, Y., \& Schultz, M. H. (2006). GMRES: A Generalized Minimal Residual Algorithm for Solving Nonsymmetric Linear Systems. Siam Journal on Scientific and Statistical Computing, 7(3), 856-869. https://doi.org/10.1137/0907058

[39] National Coal Mine Safety Administration. (2009). State Regulation of Coal and Gas Outburst Prevention and Control of China, Beijing: China Coal Industry Publishing House, 5-70.

\section{Contact information:}

Mingyun TANG, PhD

(Corresponding author)

1) State Key Laboratory of Mining Response and Disaster Prevention and Control in Deep Coal Mines, Anhui University of Science and Technology, 2) School of Mining and Safety Engineering,

Anhui University of Science and Technology,

No. 168 Taifeng Street, 232001 Huainan, Anhui Province, China

E-mail: mytang@aust.edu.cn

Pengxian ZHENG, Postgraduate

School of Mining and Safety Engineering,

Anhui University of Science and Technology,

No. 168 Taifeng Street, 232001 Huainan, Anhui Province, China

E-mail: 643395026@qq.com

Chunshan ZHENG, PhD

1) State Key Laboratory of Mining Response and Disaster Prevention and Control in Deep Coal Mines, Anhui University of Science and Technology, 2) School of Mining and Safety Engineering,

Anhui University of Science and Technology,

No. 168 Taifeng Street, 232001 Huainan, Anhui Province, China

E-mail: 930679862@qq.com

\section{Zuxiang HU, PhD}

1) State Key Laboratory of Mining Response and Disaster Prevention and Control in Deep Coal Mines, Anhui University of Science and Technology, 2) School of Mining and Safety Engineering,

Anhui University of Science and Technology,

No. 168 Taifeng Street, 232001 Huainan, Anhui Province, China

E-mail: zxhu@aust.edu.cn

\section{Jinhui WANG, $P h D$}

School of Mechanical, Aerospace and Civil Engineering,

University of Machester, George Begg Building, M13 9PL Machester, UK

E-mail: jinhui.wang@manchester.ac.uk

\section{Guanglong DAI, Prof}

1) State Key Laboratory of Mining Response and Disaster Prevention and Control in Deep Coal Mines, Anhui University of Science and Technology,

2) School of Mining and Safety Engineering,

Anhui University of Science and Technology,

No. 168 Taifeng Street, 232001 Huainan, Anhui Province, China

E-mail: gldai@aust.edu.cn 